\title{
Infecção por Mycobacterium sp. em herbívoros selvagens de cativeiro no Rio Grande do Sul: estudo retrospectivo e detecção imuno-histoquímica (2003-2015) ${ }^{1}$
}

\author{
Vanessa L. Ribeiro² ${ }^{2}$ Suyene O. Souza ${ }^{3}$, Renata A. Casagrande ${ }^{4}$, Angelica T.B. \\ Wouters $^{5}$, Flademir Wouters ${ }^{5}$, Veronica M. Rolim ${ }^{3}$, Elisandro 0. Santos ${ }^{6}$ \\ e David Driemeier ${ }^{3 *}$
}

\begin{abstract}
Ribeiro V.L., Souza S.O., Casagrande R.A., Wouters A.T.B., Wouters F., Rolim V.M., Santos E.O. \& Driemeier D. 2017. [Mycobacterium sp. in captive-reared wild herbivores in Rio Grande do Sul: a retrospective study and immunohistochemical detection (2003-2015).] Infecção por Mycobacterium sp. em herbívoros selvagens de cativeiro no Rio Grande do Sul: estudo retrospectivo e detecção imuno-histoquímica (2003-2015). Pesquisa Veterinária Brasileira 37(1):58-65. Setor de Patologia Veterinária, Universidade Federal do Rio Grande do Sul, Av. Bento Gonçalves 9090, Bairro Agronomia, Porto Alegre, RS 91540-000, Brazil. E-mail: davetpat@ufrgs.br

Tuberculosis is a debilitating infecto-contagious disease, caused by an acid-fast bacillus (AFB) that belong to different species of the Mycobacterium tuberculosis complex (MTC). Mycobacteriosis are important diseases in veterinary medicine because of their zoonotic potential and worldwide distribution, affecting all classes of vertebrates. In wild animals the mycobacteriosis have been reported mainly as a problem in captivity. There are also reports in free-ranging wildlife, endangering and hampering tuberculosis erradication programs in animal production. The diagnosis of the disease in wildlife is usually postmortem, because the tuberculin test is not standardized for wildlife species, and also it is not reliable for screening. The postmortem diagnosis is based on macroscopic findings, microscopic detection of AFB at Ziehl-Neelsen staining (ZN), and mainly isolation and identification of the agent. However, only gross and microscopic exams do not allow to distinguish the species of Mycobacterium involved. The immunostaining with polyclonal anti-Mycobacterium tuberculosis confirms tuberculosis infection, but is not specific; there may be marking of other mycobacteria. The aim of this study was to describe the histologic findings, of ZN staining and immunohistochemistry technique (IHC) of 13 cases of wildlife herbivores diagnosed with tuberculosis in the Setor de Patologia Veterinária of the Universidade Federal do Rio Grande do Sul (SPV-UFRGS) during the 2003- 2015 period. Formalin fixed paraffin embedded tissues were recut, stained with hematoxylin and eosin and ZN, and samples were submitted to the IHC (anti-M. tuberculosis marking, streptavidin-biotin peroxidase method). All animals included were adults living in captivity and belonged to the following species: llama (5/13), sambar deer (4/13), camel (1/13), red deer (1/13), Brazilian tapir $(1 / 13)$ and Nilgai antelope $(1 / 13)$. The IHC revealed immunostaining of accentuated $(4 / 13)$, moderate $(4 / 13)$ and discrete $(4 / 13)$ intensity, except in a case with insufficient
\end{abstract}

${ }^{1}$ Recebido em 14 de abril de 2016.

Aceito para publicação em 20 de julho de 2016.

${ }^{2}$ Projeto Biopesca, Av. Presidente Castelo Branco s/n, Bairro Canto do Forte, Praia Grande, SP 11700-800, Brasil.

${ }^{3}$ Setor de Patologia Veterinária, Universidade Federal do Rio Grande do Sul (UFRGS), Av. Bento Gonçalves 9090, Bairro Agronomia, Porto Alegre, RS 91540-000, Brasil. *Autor para correspondência: davetpat@ ufrgs.br

\footnotetext{
${ }^{4}$ Laboratório de Patologia Animal, Centro de Ciências Agroveterinárias, Universidade do Estado de Santa Catarina (UDESC), Av. Luís de Camões 2090, Bairro Conta Dinheiro, Lages, SC 88520-000, Brasil.

${ }^{5}$ Setor de Patologia Veterinária, Departamento de Medicina Veterinária, Universidade Federal de Lavras (UFLA), Campus Universitário, Lavras, MG 37200-000, Brasil.

${ }^{6}$ Secretaria Estadual do Meio Ambiente, Av. Borges de Medeiros 261, 11ํadar, Centro, Porto Alegre, RS, 90020-021, Brasil.
} 
material. The histological features, findings in ZN staining and IHC in the wild herbivores with tuberculosis lesions allowed the diagnosis of infection with Mycobacterium sp., turning into fast and efficient methods of diagnosis, which can help to prevent the spread of this disease in animals from the same herd.

INDEX TERMS: Mycobacterium sp., tuberculosis, herbivores, camelids, deer, histopathology, immunohistochemistry, diagnosis.

RESUMO.- A tuberculose é uma enfermidade infectocontagiosa, debilitante, causada por bacilos álcool-ácido resistentes (BAAR), pertencentes ao complexo Mycobacterium tuberculosis (CMT). As micobacterioses têm importância em Medicina Veterinária devido ao seu potencial zoonótico e sua distribuição mundial, afetando todas as classes de vertebrados. Em animais selvagens as micobacterioses têm sido um problema relatado principalmente em cativeiro. Contudo, há relatos de sua ocorrência também em animais de vida livre, colocando em risco e dificultando os programas de erradicação da tuberculose em animais de produção. 0 diagnóstico nas espécies selvagens em geral é post mortem, uma vez que o teste de tuberculina não está padronizado para essas espécies, assim como não é confiável para triagem. São consideradas para o diagnóstico lesões de necropsia, observação microscópica de BAAR na coloração de Ziehl-Neelsen (ZN) e, principalmente, isolamento e identificação do agente. No entanto, apenas os achados morfológicos macro e microscópicos não permitem distinguir a espécie de Mycobacterium envolvida. A técnica de imuno-histoquímica (IHQ) com anticorpo policlonal anti-M. tuberculosis confirma a infecção pelo CMT, mas não é específica, pois pode ocorrer marcação de outras micobactérias. As características histológicas, os achados na coloração de ZN e na IHQ de 13 casos de herbívoros selvagens diagnosticados com tuberculose no Setor de Patologia Veterinária da Universidade Federal do Rio Grande do Sul (SPV-UFRGS) no período de 2003 a 2015 são descritos. A partir das amostras em blocos de parafina foram confeccionadas novas lâminas histológicas, coradas com hematoxilina e eosina (HE) e ZN. Cortes foram submetidos à técnica de IHQ para detecção do CMT. Todos os animais eram adultos, provenientes de cativeiro e incluíram lhama (5/13), cervo sambar (4/13), camelo (1/13), cervo vermelho $(1 / 13)$, anta brasileira (1/13) e antílope Nilgai (1/13). Na IHQ observou-se imunomarcação acentuada (4/13), moderada (4/13) ou discreta (4/13), exceto em um caso, em que não havia quantidade suficiente de material. As características histológicas, bem como os achados na coloração de ZN e na técnica de IHQ confirmaram o diagnóstico de infecção por Mycobacterium sp. e foram considerados métodos rápidos e eficientes, de forma que podem ajudar na prevenção da disseminação da doença em animais.

TERMOS DE INDEXAÇÃO: Mycobacterium sp., tuberculose, herbívoros, camelídeos, cervídeos, histopatologia, imuno-histoquímica, diagnóstico.

\section{INTRODUÇÃO}

O gênero Mycobacterium compreende bactérias cocobacilares pleomórficas, aeróbicas estritas, imóveis, não filamentosas, não segmentadas, desprovidas de esporos ou cápsulas. São parasitos intracelulares obrigatórios e têm alta concentração lipídica na parede celular, que lhes confere a característica de álcool-ácido resistência. Esses lipídeos também estão envolvidos na resistência do agente aos mecanismos de defesa humorais do hospedeiro, na resistência a antimicrobianos, a desinfetantes ácidos e álcalis e a dessecação (Balian 1995, Cousins et al. 2004).

A tuberculose (TB) é uma enfermidade infectocontagiosa, crônica e debilitante (Ferreira Neto et al. 2014). Pode ser causada por diferentes espécies de bactérias pertencentes ao Complexo Mycobacterium tuberculosis (CMT) (Miller 2008, Lécu \& Ball 2011), que inclui as espécies Mycobacterium tuberculosis, M. bovis, M. africanum, M. canetti, M. microti, M. caprae e M. pinnipedii, sendo M. tuberculosis a causa predominante de TB em humanos e elefantes; e $M$. bovis em mamíferos domésticos e selvagens (Miller 2008, Corner et al. 2011).

A doença tem grande importância devido ao potencial zoonótico, ao caráter insidioso e à distribuição mundial (Ferreira Neto et al. 2014). A maioria das micobactérias do CMT tem capacidade de infectar animais selvagens, enquanto a suscetibilidade, a patogenia e a resposta imune à infecção variam amplamente entre as micobactérias e a espécie hospedeira. Embora em algumas espécies de mamíferos haja menor incidência, como equídeos e primatas neotropicais, as consequências da infecção ainda são difíceis de prever e, portanto, a erradicação da TB está potencialmente ligada à possibilidade de diagnóstico precoce nos hospedeiros domésticos e selvagens (Lécu \& Ball 2011).

Há diversos relatos de ocorrência da doença, predominantemente, em animais selvagens mantidos em cativeiro (Miller 2008, Ferreira Neto et al. 2014). Em cervídeos a infecção por Mycobacterium sp. tem sido um problema em fazendas comerciais e em animais de zoológico. Outro problema está relacionado à ocorrência da doença na fauna silvestre de vida livre que interage com animais domésticos. Em países desenvolvidos, várias espécies selvagens são naturalmente infectadas por M. bovis, como uapiti (Cervus canadensis), veado-de-cauda-branca (Odocoileus virginianus), cervo-sika (Cervus nippon), caribu (Rangifer tarandus), cervo-orelhudo (Odocoileus hemionus), cervo-dama (Dama dama) e alce (Alces alces), consideradas, então, importantes fontes de infecção para bovinos, fato que dificulta ainda mais os programas de erradicação da tuberculose bovina (Radostits et al. 2007, Miller 2008). No entanto, M. tuberculosis e M. avium também têm sido isolados (Miller 2008).

Em um estudo espanhol foi encontrada prevalência de 23,21\% (26/112) de lesões macroscópicas compatíveis com TB bovina em cervos-dama (D. dama) de vida livre, abatidos durante o período de caça de outubro e novembro de 2010 (García-Jiménez et al. 2012). Apesar disso, a doença é considerada muito rara em indivíduos de áreas pouco 
expostas às ações antrópicas ou ao contato direto com humanos (Ferreira Neto et al. 2014).

Por ser uma zoonose e devido aos impactos da enfermidade sobre a agropecuária, o diagnóstico é muito importante. Devidos à especificidade e à sensibilidade variáveis do teste de tuberculina e à dificuldade em distinguir infecções por M. bovis daquelas causadas por M. avium e outras micobactérias, testes alternativos também são realizados em casos suspeitos, como ensaio imunoenzimático (Enzyme-Linked Immunosorbent Assay; ELISA), Western Blot (Immunoblot), imunoensaio MAPIA (Multiantigen Print Immunoassay) e testes rápidos, como o teste imunocromatográfico de fluxo lateral (Lateral-Flow Immunochromatography), imunoensaio Prima-TB STAT-PAK ${ }^{\circledR}$ e o DPP Vet $\mathrm{TB}^{\circledR}$ (Immunochromatographic Dual-Path Platform) (Miller 2008, Ferreira Neto et al. 2014).

No Brasil foi realizado um estudo com uso de reação em cadeia da polimerase (PCR) para averiguar a ocorrência de tuberculose por M. bovis em cervo-do-Pantanal (Blastocerus dichotomus), no estado de Mato Grosso do Sul, com resultado negativo em todos os casos, apesar da TB ser endêmica no rebanho bovino brasileiro. Esse resultado pode ser explicado pelo fato de que, embora os cervos e o gado bovino vivam na mesma área, não há contato estreito entre essas espécies (Luna et al. 2003). Também no Brasil, em um estudo realizado com animais selvagens no Pantanal Sul-matogrossense, foram detectadas sete espécies distintas de micobactérias, incluindo M. bovis e M. avium em javali (Sus scrofa), veado-campeiro (Ozotocerus bezoarticus) e quati (Nasua nasua) através da técnica de genotipagem MIRU-VNTR (Unidades repetitivas interceptadas de Micobactérias - número variável de repetições em Tandem, do inglês "Mycobacterial Interspersed Repetitive Units - Variable Number Tandem Repeat"), a partir de isolados de BAAR (Albertti 2014).

O potencial zoonótico desses organismos representa uma preocupação para tratadores de animais e para o público em visitação de parques e zoológicos, o que justifica a necessidade de diagnóstico rápido e preciso em espécies selvagens (Miller 2008). 0 diagnóstico da tuberculose em animais selvagens se baseia nas provas de tuberculinização, embora não estejam devidamente padronizadas para essas espécies. Miller (2008) recomenda a realização de necropsia com colheita de todos os órgãos, principalmente linfonodos, de todos os animais com morte natural ou que foram submetidos a eutanásia. Dessa forma, o diagnóstico muitas vezes é baseado na identificação das lesões e na evidenciação microscópica de BAAR em ZN (Miller 2008, Lécu \& Ball 2011). 0 objetivo deste trabalho foi descrever as características histológicas, os achados na coloração de ZN e na técnica de IHQ dos casos de tuberculose em herbívoros selvagens, diagnosticados pelo Setor de Patologia Veterinária da UFRGS (SPV-UFRGS).

\section{MATERIAL E MÉTODOS}

Os arquivos de exames de necropsia e histopatológicos do período de janeiro de 2003 a dezembro de 2015 do Setor de Patologia Veterinária da Universidade Federal do Rio Grande do Sul (SPV-UFRGS) foram revisados e os casos com lesões por Mycobacterium sp. em herbívoros selvagens foram inclusos neste estudo. Dados referentes ao histórico e a lesões macroscópicas foram compilados e analisados. Foram realizados cortes histológicos com $3 \mu \mathrm{m}$ de espessura, corados por HE e ZN para avaliação microscópica. Realizou-se o estudo morfológico das lesões em diversos órgãos, principalmente pulmão.

Amostras com alterações histológicas de tuberculose de todos os animais foram submetidas à técnica de IHQ pelo método estreptavidina-biotina ligada à peroxidase. Para o bloqueio da peroxidase endógena os cortes foram incubados em solução a $10 \%$ de peróxido de hidrogênio (30 vol.) em metanol por 15 minutos. Para a recuperação antigênica utilizou-se protease XIV (Sigma) por 15 minutos, em temperatura ambiente. Para bloqueio da reação inespecífica foi utilizado leite desnatado $5 \%$ por 15 minutos. 0 anticorpo primário anti-Mycobaterium tuberculosis (GeneTex, Inc. Clone GTX 20905) foi diluído a 1:200. As lâminas foram incubadas em câmara úmida por 45 minutos a $37^{\circ} \mathrm{C}$. Posteriormente, os cortes foram incubados com anticorpo secundário biotinilado ligado a estreptavidina-peroxidase (kit LSAB-HRP, K0690, DakoCytomation) por 20 minutos cada etapa. Para a revelação foi utilizado cromógeno 3,3'-diaminobenzidina (DAB, K3468, DakoCytomation). Como controle positivo utilizou-se um corte histológico de tecido pulmonar de bovino com tuberculose. Para a intensidade de marcação foram atribuídos os graus de ausência de marcação, intensidades discreta, moderada ou acentuada.

\section{RESULTADOS}

\section{Caracterização dos casos}

No período de 2003 a 2015 foram realizados 13 diagnósticos de infecção por Mycobacterium sp. em herbívoros selvagens das espécies: lhama (Lama glama) (5/13), cervo sambar (Cervus unicolor) (4/13), camelo (Camelus bactrianus) (1/13), cervo vermelho (Cervus elaphus) (1/13), anta brasileira (Tapirus terrestris) (1/13) e antílope Nilgai (Boselaphus tragocamelus) (1/13). Todos os animais eram adultos e provenientes de dois parques zoológicos do estado do Rio Grande do Sul. Quanto ao sexo, 7/13 eram machos e 6/13 fêmeas.

A maioria dos indivíduos (12/13) vivia em um parque com área total de cerca de 320 ha. Em dois recintos coletivos eram mantidos cerca de 500 cervídeos (cervo sambar, cervo vermelho e cervo dama) e camelídeos (lhama e camelo), além de capivaras, macacos-prego, zebras, hipopótamos, avestruzes, cisnes e outros. A área aproximada de cada recinto era de 1,5 ha. Os animais ficavam em pastagem nativa e recebiam ração industrializada para equinos, cana-de-açúcar picada e forragem verde.

Quanto às manifestações clínicas, foram observados prostração $(6 / 11)$, emagrecimento $(6 / 11)$, anorexia (4/11), dispneia (5/11), nódulos múltiplos em mandíbula e pescoço (3/11) e aborto (1/11). Para três animais $(3 / 13)$ houve relato de morte sem observação de sinais clínicos prévios e para outros dois $(2 / 13)$ não foi obtida a história clínica.

Na necropsia observou-se condição corporal regular a ruim em todos os animais (13/13); cavidade torácica com grande quantidade de líquido turvo e filamentos de fibrina, aderências entre pleuras parietal e visceral e nódulos brancacentos caseosos de 0,5 a $1 \mathrm{~cm}$ de diâmetro na pleura (3/12); pulmões difusamente consolidados com múltiplos nódulos de 0,5 a $5 \mathrm{~cm}$ de diâmetro, brancacentos, caseosos, 
distribuídos por todo o parênquima pulmonar, com ranger da faca ao corte (13/13; Fig.1 e 2); fígado aumentado de volume, com evidenciação do padrão lobular (8/13) e nódulos caseosos brancoamarelados de 0,1 a $0,5 \mathrm{~cm}$ de diâmetro de distribuição aleatória, alguns desses nódulos eram firmes (3/13); linfonodos aumentados (7/13), principalmente os traqueobrônquicos e mediastínicos, cervicais superficiais e mesentéricos, que estavam brancacentos e com aspecto caseoso ao corte (5/13; Fig.3); intestino delgado com áreas avermelhadas na mucosa (3/13); rins congestos (2/13), pálidos (1/13) ou com nódulos de 0,1 a 0,5cm de diâmetro, brancoamarelados e firmes (1/13); baço difusamente aumentado (4/13) ou com nódulos de 0,1 a 0,5 cm de diâmetro, brancoamarelados e firmes no parênquima (1/13); pâncreas com nódulos brancacentos (1/13); saco pericárdico acentuadamente espessado, com deposição de fibrina na superfície externa e múltiplos nódulos de até 0,5 cm de diâmetro, brancacentos e caseosos (1/13), atrofia serosa da gordura epicárdica e placas brancacentas elevadas e irregulares na parede do átrio direito e áreas brancacentas de $0,1 \mathrm{~cm}$ no miocárdio (1/13).

\section{Caracterização histopatológica}

No exame histopatológico dos pulmões de todos os casos observaram-se extensas áreas de necrose caseosa com mineralização discreta a moderada, circundadas por inflamação granulomatosa composta por macrófagos, células epitelioides, células gigantes multinucleadas de Langhans e linfócitos, com tecido conjuntivo fibroso periférico (13/13; Fig.4A). Em alguns casos havia ainda moderado a acentuado edema rico em proteína (5/13), células gigantes e fibrina $(7 / 13)$ preenchendo os alvéolos. Nos linfonodos havia necrose caseosa com mineralização moderada, circundada por inflamação granulomatosa (2/13; Fig.4B) e discreto a abundante tecido conjuntivo colagenizado (5/13); no baço havia extensas áreas de necrose caseosa e mineralização moderada, circundadas por inflamação granulomatosa, delimitadas por tecido conjuntivo colagenizado (1/13); no encéfalo foram evidenciadas áreas de necrose multifo-

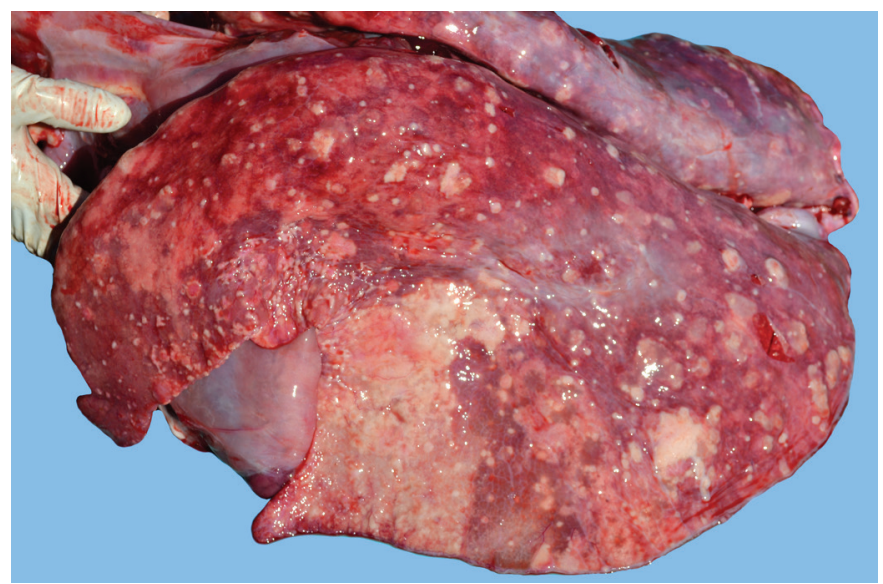

Fig.1. Alterações macroscópicas da tuberculose em lhama (Lama glama). Pulmões consolidados e com múltiplos nódulos brancacentos, caseosos de 0,5 a $5 \mathrm{~cm}$ de diâmetro, distribuídos por todos os lobos.

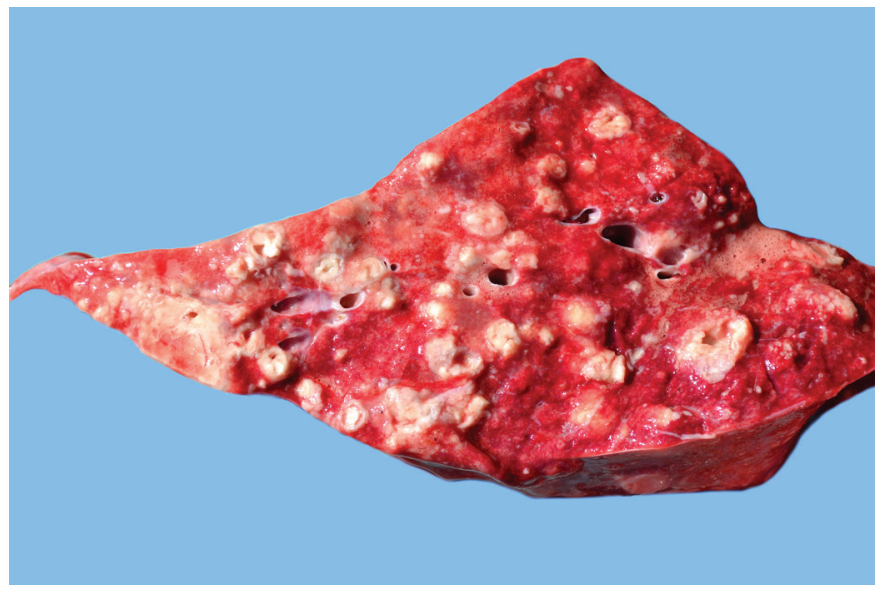

Fig.2. Alterações macroscópicas da tuberculose em lhama (Lama glama). Pulmão (superfície de corte) com múltiplos nódulos brancacentos caseosos.

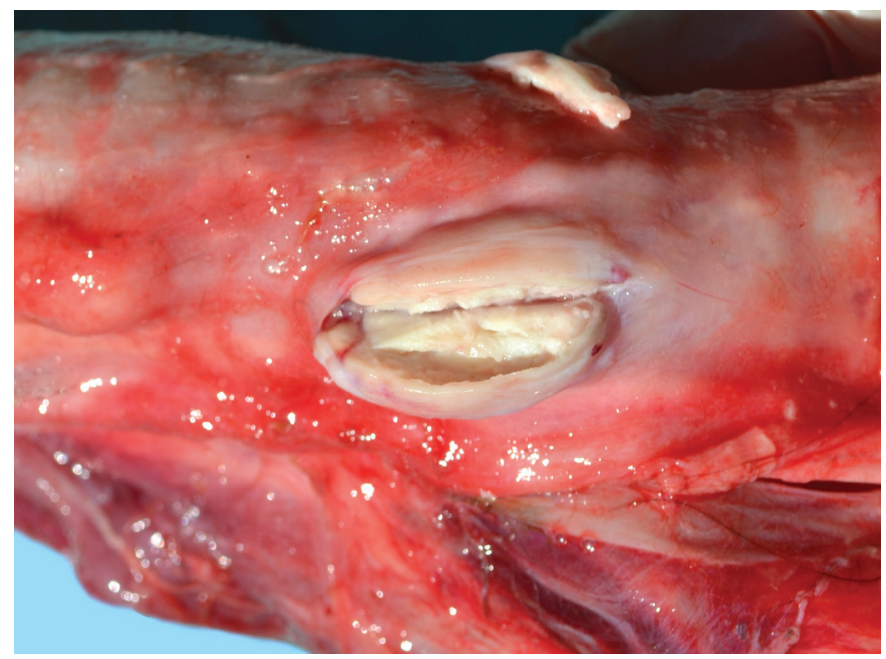

Fig.3. Alterações macroscópicas da tuberculose em lhama (Lama glama). Linfonodo traqueobrônquico difusamente brancacento e caseoso.

cal moderada em meninges, também circundadas por inflamação granulomatosa (1/13); no intestino delgado foi observada necrose caseosa circundada por macrófagos, células epitelioides, células de Langhans e linfócitos, com discreta proliferação de tecido fibrovascular em placas de Peyer (1/13); nos rins havia focos de necrose caseosa cercados por macrófagos, células gigantes e linfócitos e havia glomerulonefrite membranoproliferativa discreta (2/13); no fígado verificaram-se focos de necrose caseosa cercados por macrófagos, macrófagos epitelioides e linfócitos, além de discreta proliferação fibrovascular periférica e congestão centrolobular (3/13); no saco pericárdico havia necrose caseosa multifocal a coalescente cercada por infiltrado acentuado de macrófagos epitelioides e linfócitos, fibrina, ocasionais neutrófilos e proliferação acentuada de tecido conjuntivo (1/13).

Na coloração de ZN foram evidenciados BAAR em quantidade grande $(6 / 13)$, moderada $(1 / 13)$ ou escassa $(4 / 13)$ em áreas de necrose e no citoplasma de macrófagos e de células de Langhans no parênquima pulmonar (Fig.5A) e, 
em um caso, em linfonodo mandibular. Em dois casos não foi possível verificar a presença de BAAR.

\section{Caracterização imuno-histoquímica}

Observou-se imunomarcação acentuada (4/13), moderada $(4 / 13)$ ou discreta $(4 / 13)$ em áreas de necrose, livre ou no citoplasma de macrófagos necróticos, em macrófagos epitelioides e em células gigantes nos pulmões (Fig.5B). Em um caso não foi possível realizar a técnica de IHQ devido à quantidade insuficiente de material. No caso com meningite houve marcação discreta em células de Langhans na meninge e, em outro, com lesão em linfonodo mandibular, foi evidenciada marcação discreta nas áreas de necrose, livre ou no citoplasma de macrófagos necróticos e em macrófagos epitelioides e células gigantes.

\section{DISCUSSÃO}

O diagnóstico clínico da tuberculose tem validade limitada em decorrência da característica insidiosa da enfermidade e dos sinais clínicos inespecíficos (Ferreira Neto et al. 2014). Diferentes técnicas de diagnóstico por imagem podem auxiliar no diagnóstico da TB, mas são apenas informativas sobre a localização e o aspecto das lesões. 0 exame radiográfico pode ser limitado, dadas as características anatômicas das espécies animais de zoológico (por exemplo, em ungulados acima de $250 \mathrm{~kg}$ as dimensões torácicas inviabilizam a utilização da técnica), as imagens de lesões podem estar ausentes ou podem ser demasiadamente pequenas para detecção radiográfica. Além disso, em algumas espécies, lesões mineralizadas são raras, como em felinos e primatas não-humanos (Lécu \& Ball 2011, Ferreira Neto et al. 2014). Ultrassonografia de alta frequência, tomografia computadorizada e ressonância magnética poderiam ser úteis para a detecção de lesões em linfonodos não-palpáveis, como os intratorácicos, ou quando a conformação anatômica impede a palpação. Dessa forma, o tamanho dos pacientes, a limitação de abordagem clínica e imobilização física e/ou química, a disponibilidade de dispositivos e o custo podem impedir a utilização desses métodos em animais de zoológico (Lécu \& Ball 2011). Nos animais avalia-
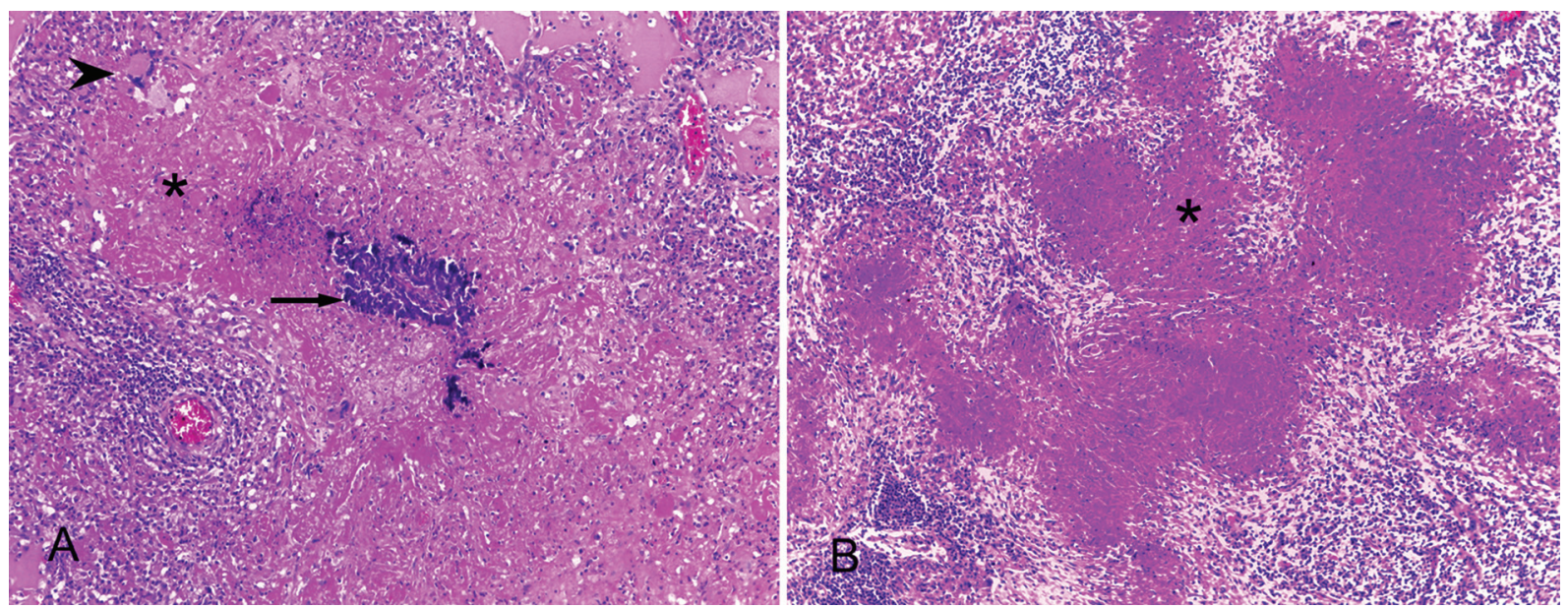

Fig.4. Achados histológicos das lesões de tuberculose em herbívoros selvagens. (A) Cervo sambar (Cervus unicolor): extensa área de necrose caseosa (asterisco) com mineralização moderada (seta) e célula gigante multinucleada de Langhans em pulmão (ponta de seta). HE, obj.10x. (B) Anta (Tapirus terrestris): extensa área de necrose caseosa (asterisco) em linfonodo. HE, obj.10x.
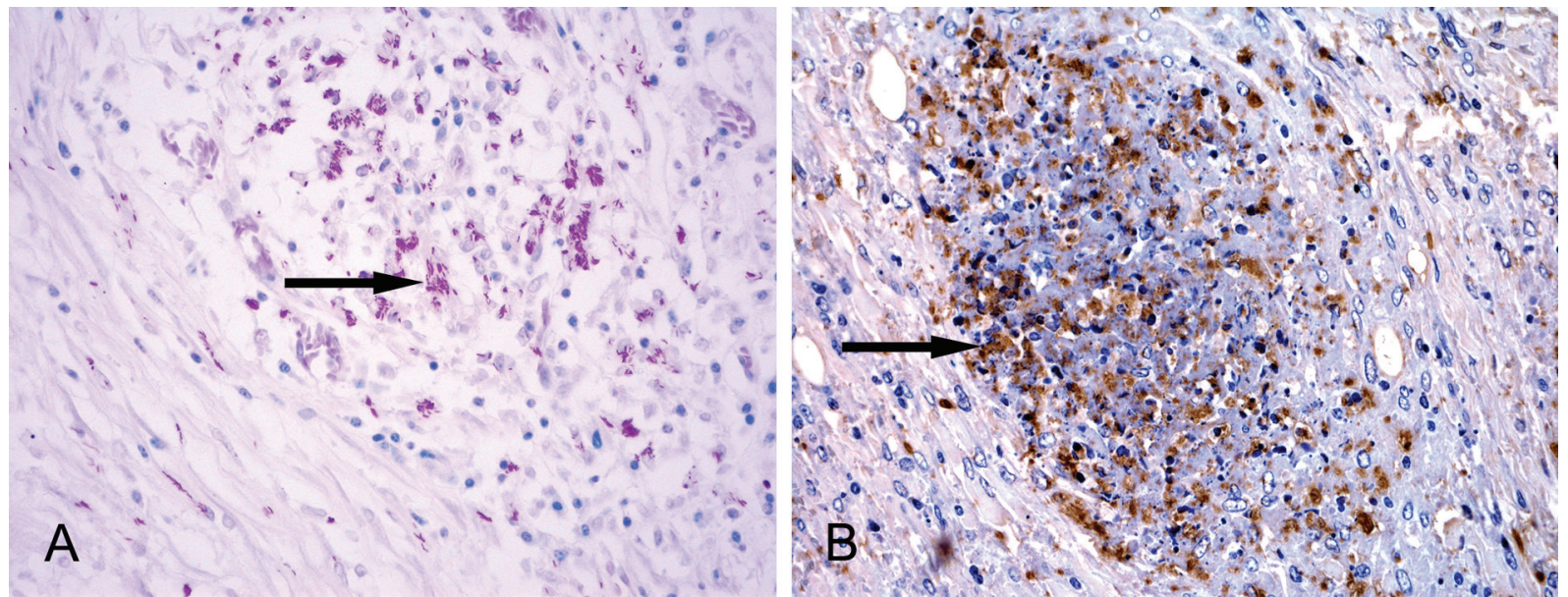

Fig.5. Achados histoquímicos e imuno-histoquímicos em lesões de tuberculose em pulmão de lhama (L. glama) (A) Evidenciação de grande quantidade de bactérias álcool-ácido-resistentes em área de necrose (seta). Ziehl-Neelsen, obj.40x (B) Marcação imuno-histoquímica anti-Mycobacterium tuberculosis em área de necrose caseosa (seta). Método da Estreptavidina-biotina ligada à peroxidase, obj.40x. 
dos não havia histórico de realização de técnicas de diagnóstico por imagem.

Portanto, o diagnóstico in vivo da tuberculose em animais selvagens ainda é um desafio e baseia-se na realização de provas imunológicas intradérmicas de hipersensibilidade tardia (tuberculinização) usando extratos proteicos purificados (purified protein derivative, PPD) de micobactérias (tuberculina). Esse método foi padronizado para humanos e, posteriormente, para bovinos. Em animais selvagens o emprego dessa técnica é sujeito a uma grande quantidade de variáveis, que confere ao procedimento baixos graus de sensibilidade e especificidade para diversas espécies (Ferreira Neto et al. 2014).

0 diagnóstico dos casos de tuberculose foi post mortem, baseado nas características histológicas, histoquímicas e imuno-histoquímicas. Nenhum teste ante mortem tem total confiabilidade para o diagnóstico de TB em animais de zoológico. A abordagem para exames de rotina e exame clínico de casos suspeitos exige a aplicação de várias modalidades de exame. É importante ressaltar que a maioria dos testes não é validada para espécies selvagens e exóticas e os exames com base em resposta imunológica, em especial, podem mostrar variação significativa entre espécies (Miller 2008).

Os animais acometidos eram cervídeos, lhamas, anta e antílope, todos de cativeiro. Em relação às espécies acometidas por TB, há diversos relatos de ocorrência da doença, predominantemente, em animais mantidos em cativeiro; primatas, bovídeos, cervídeos e outros artiodáctilos (antílopes, girafas, camelídeos sul-americanos e do velho mundo, entre outros), elefantes asiáticos, perissodáctilos (antas, equídeos, rinocerontes), carnívoros, pinípedes, marsupiais, psitacídeos e outras aves (Miller 2008, Lécu \& Ball 2011, Ferreira Neto et al. 2014). 0 papel potencial da fauna silvestre na manutenção e na propagação da infecção por $M$. bovis em animais domésticos tem sido amplamente divulgado em vários países. São citadas diferentes espécies de cervídeos, como o cervo-vermelho (C. elaphus) na Nova Zelândia e na Grã-Bretanha (Delahay et al. 2001) e o veado-de-cauda-branca (O. virginianus) nos Estados Unidos (O'Brien et al. 2001). Infecção por Mycobacterium bovis foi também relatada em cervo-dama (D. dama) em vida livre (Rhyan \& Saari 1995, Johnson et al. 2008).

A tuberculose foi diagnosticada em seis camelídeos e em uma anta. A doença tem sido descrita em camelídeos sul-americanos e do velho mundo e os testes de rotina utilizados em cervídeos também têm sido usados regularmente para camelídeos e podem ser exigidos para transporte interestadual e internacional desses animais (Miller 2008). A infecção pulmonar por M. bovis e M. tuberculosis já foi relatada em antas em cativeiro, bem como o isolamento de $M$. avium (Mangini 2014).

Neste estudo foram observados vários sinais clínicos, especialmente emagrecimento progressivo, anorexia, prostração, dispneia, nódulos em região de mandíbula e pescoço, porém três animais tiveram morte sem sinais clínicos prévios e um animal abortou. Os sinais clínicos da TB são raramente vistos antes da morte em animais de zoológico e muitos animais infectados têm doença subclínica até fase avançada da doença. Esta é uma característica comportamental importante em animais selvagens; não demonstram sinais clínicos para evitar a predação em vida livre. Contudo, alguns sinais clínicos podem estar presentes e devem ser considerados para o diagnóstico, como perda de peso crônica, fraqueza, dispneia, tosse e aumento de volume em linfonodos. Tosse e dispneia podem indicar estágio final e irreversível da forma pulmonar da TB e o sinal clínico mais frequentemente notado entre mamíferos selvagens é perda de peso crônica (Miller 2008, Lécu \& Ball 2011, Ferreira Neto et al. 2014). Portanto, a quarentena deve ser realizada como rotina em animais introduzidos em coleções zoológicas de espécies sensíveis (Miller 2008).

No exame histopatológico dos pulmões de todos os casos observaram-se extensas áreas de necrose caseosa com mineralização discreta a moderada, cercadas por macrófagos, macrófagos epitelioides e de Langhans e linfócitos, circundados por tecido conjuntivo fibroso. Em um estudo realizado por Rhyan \& Saari (1995), foram comparadas as lesões histológicas de tuberculose por Mycobacterium bovis de bovinos, cervo-dama, cervo-sika, cervo-vermelho e sua subespécie "rocky mountain" (Cervus elaphus nelsoni), sendo que algumas diferenças morfológicas foram notadas. Nas lesões de cervo "rocky mountain" e cervo-vermelho havia marcada variação e, muitas vezes, as lesões diferiam daquelas encontradas nos bovinos; geralmente havia mineralização periférica dispersa ao invés de mineralização central e continham mais neutrófilos e menor número de células gigantes que as lesões de bovinos. As lesões em cervo-dama continham mais células gigantes, mas foram indistinguíveis de lesões em cervos "rocky mountain". As lesões em cervo-sika continham mais células gigantes e menos neutrófilos do que as lesões de bovinos ou outras espécies de cervídeos. Células gigantes de cervo-sika eram maiores e continham mais núcleos do que células gigantes nas outras espécies.

Foram encontradas áreas de necrose multifocal moderada em meninge, circundadas por macrófagos, macrófagos epitelioides, células gigantes multinucleadas e linfócitos em um cervo-sambar (Cervus unicolor), sem descrição de alteração macroscópica no sistema nervoso central (SNC). As lesões da tuberculose têm distribuição característica no SNC, com predominância de lesões em meninges da base do encéfalo, denominada meningite basilar tuberculosa. A lesão pode se estender para o parênquima encefálico, com meningoencefalite (Barros et al. 2006).

$\mathrm{Na}$ coloração de ZN foram evidenciados BAAR em quantidades variáveis em áreas de necrose e no citoplasma de macrófagos e de células gigantes multinucleadas no parênquima pulmonar e, em um caso, no linfonodo mandibular. A evidenciação das micobactérias fundamenta-se na característica de BAAR, já que as células coradas com fucsina não podem ser descoradas pelo álcool ou ácido, conferindo às bactérias coloração vermelha-viva em técnicas como a de ZN, a mais comumente empregada (Ferreira Neto et al. 2014). Porém, segundo Sakamoto (1997) a coloração de ZN, a despeito de ser rápida e barata, só consegue revelar a presença de BAAR em concentrações superiores a $10^{4}$ bactérias/mL. 0 diagnóstico citológico e/ou histológico da tu- 
berculose é baseado na observação microscópica das micobactérias. Quando a quantidade de bacilos é muito pequena, o local preferencial de pesquisa histopatológica é ao redor dos focos de necrose caseosa, em macrófagos epitelioides e de Langhans. Apenas a morfologia, tanto macro quanto microscópica das lesões da tuberculose, não permite distinguir qual a espécie de Mycobacterium envolvida, uma vez que as lesões induzidas pelas diversas espécies de micobactérias têm semelhanças entre si (Andreazza et al. 2015).

Em dois casos não houve evidenciação de BAAR na coloração de ZN, que pode ter sido um falso-negativo por escassez de bactérias. As técnicas de coloração de ZN e cultura podem apresentar baixa sensibilidade, como demonstrado em um estudo que comparou os métodos rotineiros de diagnóstico de TB em bovinos leiteiros (histopatologia, histoquímica e cultura) com PCR e Nested-PCR. A baixa sensibilidade da cultura e da coloração de ZN foi justificada, entre outras causas, pela escassez de bactérias em lesões crônicas, com extensa fibrose, necrose e mineralização (Estrada-Chávez et al. 2004). Em um estudo comparando técnicas de detecção post mortem de M. bovis em veado-de-cauda-branca, o número de BAAR foi muito variável (escassos até numerosos) de caso para caso. Além disso, a localização dos BAAR foi variável; foram mais frequentemente vistos no citoplasma de células gigantes de Langhans, menos frequentemente no citoplasma de macrófagos ou livre em meio a restos necróticos (Fitzgerald et al. 2000).

Isolamento com identificação do agente micobacteriano é considerado padrão-ouro para o diagnóstico, mas o cultivo exige métodos e meios especiais e, principalmente, requer um período prolongado para obtenção de resultados, exigindo duas semanas até três meses para micobactérias de crescimento lento, que incluem todas as micobactérias do CMT (Witmer et al. 2003, Lécu \& Ball 2011, Ferreira Neto et al. 2014). As ferramentas utilizadas nos casos descritos são mais rápidas e permitem a tomada de medidas de controle imediatas.

A técnica de IHQ mostrou ser muito eficaz na identificação de bactérias do gênero Mycobacterium em tecidos de animais afetados. Este método pode ser particularmente útil quando não há material disponível para isolamento bacteriano. Além disso, os resultados são rápidos quando comparados com o período necessário para o crescimento das micobactérias. Embora a histopatologia e a coloração de ZN sejam adequadas para identificar micobactérias, possuem menos sensibilidade e especificidade que a IHQ; esta pode identificar micobactérias em lesões granulomatosas que foram negativas na histologia e na histoquímica (Paolicchi et al. 2001). A coloração de ZN mostrou distribuição semelhante à observada na IHQ, porém os anticorpos comerciais existentes não distinguem os diferentes tipos de micobactérias, com reações cruzadas entre elas (micobactérias tuberculosas, micobactérias não tuberculosas e bacilos da lepra) (Alves et al. 1999). O tempo de fixação em formol é considerado um fator limitante na técnica de IHQ, pois a fixação prolongada em formalina pode resultar em falha de detecção do antígeno (Webster et al. 2009). Esta situação não foi evidenciada no presente estudo, visto que houve imunomarcação na maioria dos casos.
A probabilidade de transmissão zoonótica entre animais de zoológico e humanos depende da combinação de vários eventos, relacionados ao estado imunológico e ao tempo de exposição a animais infectados. É maior em manipuladores diários desses animais do que em pessoas com contato breve, como público em visitação (Lécu \& Ball 2011). 0 diagnóstico de TB em uma coleção zoológica deve ser realizado, com restrição de trânsito animal quando necessária, levando em consideração questões associadas com a saúde humana e a eutanásia de animais infectados, mesmo que aparentemente saudáveis, uma vez que não se recomenda o tratamento, devido à dificuldade de eliminação do agente e de seu potencial zoonótico (Miller 2008).

\section{CONCLUSÕES}

As características histológicas aliadas aos achados na coloração de ZN possibilitaram o diagnóstico de lesões por Mycobacterium sp. em herbívoros selvagens.

A técnica de IHQ foi eficaz na identificação do CMT em tecidos, sendo o método empregado particularmente útil quando não há material disponível para isolamento bacteriano e os resultados são rápidos.

No presente estudo, o diagnóstico foi fundamental para realização de medidas preventivas em relação a propagação da doença nos parques zoológicos.

\section{REFERÊNCIAS}

Albertti L.A.G. 2014. Detecção de micobactérias em animais silvestres em sub-regiões do Pantanal Sul-mato-grossense. Tese de Doutorado em Saúde Animal, Universidade Federal do Mato Grosso do Sul, Campo Grande, MS. 52p.

Alves V.A.F., Bacchi C.E. \& Vassalo J. 1999. Manual de imuno-histoquímica. Sociedade Brasileira de Patologia, São Paulo.

Andreazza D., Boos G.S., Boabaid F.M., Wouters A.T.B., Wouters F., Souza S.O., Menegat M.B. \& Driemeier D. 2015. Caracterização histológica e imuno-histoquímica das lesões de tuberculose em bovinos e de linfadenite granulomatosa em suínos. Pesq. Vet. Bras. 35(2):129-136.

Balian S.C. 1995. Estudo das linfadenites tuberculóides em suínos abatidos em matadouro da região da Grande São Paulo, no período de 1993 a 1994. Aspectos macroscópicos, histopatológicos e pesquisa de micobactérias. Dissertação de Mestrado em Epidemiologia Experimental e Aplicada a Zoonoses, Faculdade de Medicina Veterinária e Zootecnia, Universidade de São Paulo, São Paulo. 78p.

Barros C.S.L., Driemeier D., Dutra I.S. \& Lemos R.A.A. 2006. Tuberculose, p.81-86. In: Ibid. (Eds), Doenças do Sistema Nervoso de Bovinos no Brasil. Vallée, São Paulo.

Cousins D.V., Huchzermeyer H.F.K.A., Griffin J.F.T., Brückner G.K., Van Rensburg I.B.J. \& Kriek N.P.J. 2004. Tuberculosis, p.1973-1993. In: Coetzer J.A.W. \& Tustin R.C. (Eds), Infectious Diseases of Livestock. 2nd ed. Oxford University Press, Cape Town.

Corner L.A.L., Murphy D. \& Gormley E. 2011. Mycobacterium bovis infection in the Eurasian bdger (Meles meles): the disease, pathogenesis, epidemiology and control. J. Comp. Pathol. 144(1):1-24.

Delahay R.J., Cheeseman C.L. \& Clifton-Hadley R.S. 2001. Wildlife disease reservoirs: the epidemiology of Mycobacterium bovis infection in the European badger (Meles meles) and other British mammals. Tuberculosis 81(1/2):43-49.

Estrada-Chávez C., Otero F.D., Díaz C.A., Villegas-Sepúlveda N., González R.P. \& Salazar D.G. 2004. Concordancia de la PCR y métodos rutinarios para el diagnóstico de tuberculosis bovina. Vet. Méx. 35(3):225-236.

Ferreira Neto J.S., Valvassoura T. \& Catão-Dias J.L. 2014. Avanços no diagnóstico da tuberculose em animais selvagens, p. 1382-1388. In: Cubas 
Z.S., Silva J.C.R. \& Catão-Dias J.L. Tratado de animais selvagens. $2^{\underline{a}}$ ed., Roca, São Paulo.

Fitzgerald S.D. Kaneene J.B., Butler K.L., Clarke K.R., Fierke J.S., Schmitt S.M., Bruning-Fann C.S., Mitchell R.R., Berry D.E. \& Payeur J.B. 2000. Comparison of postmortem techniques for the detection of Mycobacterium bovis in white-tailed deer (Odocoileus virginianus). J. Vet. Diagn. Invest. 12(4):322-327.

García-Jiménez W.L., Fernández-Llario P., Gómez L., Benítez-Medina J.M., García-Sánchez A., Martínez R., Risco D., Gough J., Ortiz-Peláez A., Smith N.H., Hermoso de Mendoza J. \& Salguero F.J. 2012. Histological and immunohistochemical characterisation of Mycobacterium bovis induced granulomas in naturally infected Fallow deer (Dama dama). Vet. Immunol. Immunopathol. 149(1/2):66-75.

Johnson L.K., Liebana E., Nunez A., Spencer Y., Clifton-Hadley R., Jahans K., Ward A., Barlow A. \& Delahay R. 2008. Histological observations of bovine tuberculosis in lung and lymph node tissues from British deer. Vet. J. 175(3):409-412.

Lécu A. \& Ball R. 2011. Mycobacterial infections in zoo animals: relevance, diagnosis and management. Int. Zoo Yearb. 45(1):183-202.

Luna J.O., Santos M.A., Durigon E.L., Araújo Júnior J.P. \& Duarte J.M. 2003. Tuberculosis survey of free-ranging marsh deer (Blastocerus dichotomus) in Brazil. J. Zoo Wildl. Med. 34(4):414-415.

Mangini P.R. 2014. Perissodactyla - Tapiridae (Anta), p.1025-1026. In: Cubas Z.S., Silva J.C.R. \& Catão-Dias J.L. (Eds), Tratado de Animais Selvagens. 2a ed., Roca, São Paulo.

Miller M. 2008. Current diagnostic methods for tuberculosis in zoo ani- mals, p.10-19. In: Fowler M.E. \& Miller R.E. (Eds), Zoo and Wild Animal Medicine. Saunders Elsevier, Philadelphia.

O’Brien D.J., Fitzgerald S.D., Lyon T.J., Butler K.L., Fierke J.S., Clarke K.R., Schmitt S.M., Cooley T.M. \& Derry D.E. 2001. Tuberculous lesions in free-ranging white-tailed deer in Michigan. J. Wildl. Dis. 37(3):608-613.

Paolicchi F.A., Vagnozzi A., Morsella C.G., Verna A.E., Massone A.R., Portiansky E.L. \& Gimeno E.J. 2001. Paratuberculosis in red deer (Cervus elaphus): an immunohistochemical study. J. Vet. Med. 48(4):313-320.

Radostits O.M., Gay C.C., Hinchcliff K.W. \& Constable P.D. 2007. Diseases associated with bacteria, p.1007-1017. In: Ibid. (Eds), Veterinary Medicine: a textbook of the diseases of cattle, horses, sheep, pigs and goats. 10th ed. Saunders Elsevier, Edinburgh.

Rhyan J.C. \& Saari D.A.A. 1995. Comparative study of the histopathologic features of bovine tuberculosis in cattle, fallow deer (Dama dama), sika deer (Cervus nippon), and red deer and elk (Cervus elaphus). Vet. Pathol. 32(3):215-220.

Sakamoto S.M. 1997. Detecção e identificação de Mycobacterium bovis pela reação em cadeia polimerase (PCR), Dissertação de Mestrado em Epidemiologia Experimental e Aplicada a Zoonoses, Faculdade de Medicina Veterinária e Zootecnia, Universidade de São Paulo, São Paulo. 43p.

Webster J.D., Miller M.A., Dusold D. \& Ramos-Vara J. 2009. Effects of prolonged formalin fixation on diagnostic immunohistochemistry in domestic animals. J. Histochem. Cytochem. 57(8):763-761.

Witmer G., DeLiberto T., Ver Cauteren K. \& Butchko P. 2003. Mycobacterial diseases in wildlife, p.309-315. In: Ibid. (Eds), Wildlife Damage Management Conference. USDA National Wildlife Research Center, Fort Collins. 